\title{
Examination of the change of the overall heat transfer coefficients of building structures in function of water content
}

\author{
Dr. Ákos Lakatos, Dr. Ferenc Kalmár \\ University of Debrecen, Faculty of Engineering, \\ Department of Building Services and Building Engineering, Debrecen, Hungary \\ H-4028 Debrecen, Ótemető str. 2-4. \\ Tel:+36-52-415-155 \\ Fax:+36-52-415-155/77713 \\ email: alakatos@eng.unideb.hu, fkalmar@eng.unideb.hu
}

Corresponding author: Dr Ákos Lakatos, alakatos@eng.unideb.hu

\begin{abstract}
Nowadays the most applied insulation material in the building sector is the expanded polystyrene (EPS). Different types of EPS are used but more and more is spread the graphite added type. Our research focuses on the analysis of heat conductivity and sorption properties of EPS since these two physical properties are the most important from energy saving point of view. In this paper the variation of heat transfer coefficient of an insulated wall is analysed in function of humidity content of insulation material. Brick and concrete walls with $0.4 \mathrm{~m}$ thicknesses were chosen for substrate and $0.1 \mathrm{~m}$ EPS $(30,100,150,200$ and the so-called grey EPS) materials were applied as insulating layer. The investigations of sorption behaviour of the materials are important from the point of view of fundamental research and building technology as well. Sorption data taken from our previous measurements results were used for predicting the change of the overall heat-transfer coefficients of different wall structures constituted like this.
\end{abstract}




\section{Practical application}

The present technical note is based on our previous measurement results. Water can cause undesirable changes in the building structures and introduced in this article. During the fixing procedure of the additional insulating of a given building bad weather conditions (high relative humidity and/or low external temperature) can dominate. These phenomena can be imagined for building new houses. By the "in-building" of the moisture into the wallstructure, numerous and measurable change can happen in the U-value of the building envelope. The presented changes are estimations only, but can be used and can help for planning and executing the insulating process.

\section{Acknowledgements}

The work of Ferenc Kalmár is supported by TÁMOP-4.2.2.A-11/1/KONV-2012-0041 project. The project is co-financed by the European Union and the European Social Fund. The research of Akos Lakatos was supported by the European Union and the State of Hungary, cofinanced by the European Social Fund in the framework of TÁMOP 4.2.4. A/2-11-1-20120001 'National Excellence Program'.

\section{Introduction}

By additional insulating one can not only reduce heat losses so probably energy bills of the buildings, but also can make his house more comfortable. Efficient building insulating can shorten the heating period as well as the effects of the thermal bridges can be reduced. The energy minimizing, and reducing the $\mathrm{CO}_{2}$, as well as the green house gases are well known concepts. Other reasons for the "thermal packing" of the buildings are the extension of the lifetime of the buildings, the protection of the bearing layer against the ice and mechanical impacts furthermore the market value of the buildings are increasing. EPS is thought to be a 
reasonable insulating medium which exhibits consistent thermal performance. Its low prize and relatively low thermal conductivity can anticipate its extensive application.

\section{Materials and methods}

In this publication we give predictions for the change of the overall heat transfer coefficients of the building structures in function of water content. Water can cause undesirable changes in the physical, chemical and mechanical properties of the solid materials. It is reported in Ref 1-7. Our calculations are based on our previous measurement results $[5,6]$.

\subsection{Measurement methods}

Both the sorption and the thermal conductivity measurements were carried out after drying the samples in a VentiCell drying instrument. With this device materials can be dried setting different air temperatures (up to $523 \mathrm{~K}$ ). It works with hot air circulation using an inbuilt ventilator. For the sorption measurements three EPS samples with $8 \mathrm{~cm} \times 8 \mathrm{~cm} \times 5 \mathrm{~cm}$ geometries were prepared from the original pieces in order to perform the measurements on three specimens from the same material. The expanded polystyrene materials were produced in the Cellplast Plastic Ltd in Hajduszoboszló. The main steps through the sample preparations were the followings. After the preparation of the raw material, the samples were taken to the pre-expander and were heat-treated at $368 \mathrm{~K}$. From the pre-expander the dried materials were exposed to a half day conditioning. Then the moulding and the second conditioning of the semi-prepared samples came after. On completion of the sample preparing they can be dimensioned. The results were obtained by averaging of three measurements. Before treating the samples in the CLC climatic chamber, samples were dried to changeless weight at $343 \mathrm{~K}$ under normal atmospheric pressure $\left(10^{5} \mathrm{~Pa}\right)$ at all times. This temperature was chosen because it is fairly under the melting point of the polystyrene (about $373 \mathrm{~K}$ ) and 
during the dehydrating process at this temperature; the material does not suffer losses in its physical and chemical properties. To determine the sorption curves (moisture content of material in function of relative humidity $(\mathrm{RH} \%)$ of air at $293 \mathrm{~K})$ the samples were kept in the CLC chamber under 25, 50, 63, 76 and $90 \%$ RH for 240 minutes. The moisture content $(\omega \%)$ of a solid material can be calculated from the next simple equation (Eq. 1):

$$
\omega=\frac{m_{w}-m_{d}}{m_{d}}
$$

where $\mathbf{m}_{\mathbf{d}}$ and $\mathbf{m}_{\mathbf{w}}$ are the mass of the dried and the damped samples respectively.

For measuring the thermal conductivity of each polystyrene samples, Lambda 2000 Heat flow meter (HFM) was used. This equipment is designed to determine the thermal conductivity of insulation materials in accordance with standard ASTM C518 and ISO 8301 protocols. A sample with $30 \mathrm{~cm} \times 30 \mathrm{~cm} \times 5 \mathrm{~cm}$ geometry is placed in the test section between two plates which are maintained at different temperatures $\left(T_{1}=285 \mathrm{~K}\right.$ and $T_{2}=295 \mathrm{~K}$, with $\left.T_{\text {mean }}=290 \mathrm{~K}\right)$ during the test. After achieving thermal equilibrium and establishing a uniform temperature gradient throughout the sample, thermal conductivity is determined. To determine the thermal conductivity of a sample, three independent measurements were carried out. The thermal conductivity of analysed material was the mean value of the three measured results. The measurement methods and orders are clearly written in our previous publications. [5-8].

\subsection{The calculation procedure}

For evaluating the initial thermal conductivities $\left(\lambda_{0}\right)$ of the different EPS materials $\chi=0,42$ (the so-called correction factor) was applied using the following equation regarding to the MSZ-04-140-2:1991 standard.

$$
\lambda_{0}=\lambda_{\text {measured }} \times(1+\chi)
$$


where $\lambda_{\text {measured }}$ is the measured thermal conductivity reported in Ref 5 before.

$$
\lambda=\lambda_{0} \times\left(1+\frac{\omega \times Z}{100}\right)
$$

For calculating the change of the thermal conductivity of a given material in function of moisture content the above mentioned equation (Eq. 3) can be used [9]. In this equation $\lambda$ is the predicted thermal conductivity, $\omega$ is the moisture content [5] and $\mathrm{Z}$ is constant and can be found in Table 1 (taken from Ref 9). There are some investigations, measurements and simulations for predicting the thermal conductivity at given moisture content degree. The most of them are presenting linear dependency, some of them are presenting initially linear and then polynomial/exponential equation so plots $[5,10,11,12]$. By using the following equations the thermal resistance of a given wall structure and the overall heat transfer coefficient can be calculated:

$$
\sum R=\frac{1}{\alpha_{i}}+\sum \frac{d}{\lambda}+\frac{1}{\alpha_{e}}
$$

where, $\alpha_{i, e}$ are the heat transfer coefficients on the surface, $\frac{1}{\alpha_{i}}$ and $\frac{1}{\alpha_{e}}$ are giving the internal and the external surface resistivities respectively, $d$ is the thickness of the wall (in $\mathrm{m}$ ) represented in Table 1, furthermore $\lambda$ is the above mentioned thermal conductivity. So that, the overall heat transfer coefficients can be calculated.

$$
U=\frac{1}{R}
$$

\section{Results and discussions}

\subsection{The U-values in function of moisture content}


Before representing the calculations some assumptions have to be noticed. The values in the first and second rows of Tables 2, 3, 4, 5 and 6 representing the sorped amount of water in function of the relative humidity belonging to the different EPS materials. Here the measured and previously introduced [5] moisture contents of the given materials can be found. For calculating the change of the thermal conductivities of the EPS, brick and concrete the above mentioned moisture content values were applied. By using these data values, Eq. 2 and 3 the thermal conductivities of the wetted EPS, concrete and brick materials can be calculated. It is feasible to calculate the overall heat transfer coefficients for the 0.4 m_Concrete/0.1m_EPS and 0.4 m_Brick/0.1 m EPS systems by applying Eq. 5. For the EPS materials $0.1 \mathrm{~m}$ thickness was chosen to be significantly under the $\mathrm{U}=0.45 \mathrm{~W} / \mathrm{m}^{2} \mathrm{~K}$ value. This value is the requirement for the overall heat-transfer coefficients for outer walls in Hungary. It can be found in the decree of the minister without portfolio in Hungary No 2006/7. For thicknesses of EPS 30, 100, 150, 200 and Grey to meet the requirements as additional insulating in combination with $0.4 \mathrm{~m}$ brick or concrete calculated values are presented in Table 7. One can see that thicknesses are varying from 0.07 to 0.09 .

As results, we plotted our estimated values, since on Figure 1.a and b one can see the estimated U-values (Concrete+EPS and Brick+EPS) taken from tables 2, to 6 in function of the moisture contents. Linear plots can be found as expected from Eq. 3 and 5. In these diagrams the requirement for the U-value as well as a suggested $\mathrm{U}$-value are represented. One can see that with this thickness $(0.1 \mathrm{~m}$ for EPS $)$ neither of them can reach this suggested value. Observable either the increasing U-values in function of moisture content but none of the estimated U-values reaches the required $0.45 \mathrm{~W} / \mathrm{m}^{2} \mathrm{~K}$. All of the data points were fitted with linear functions and follows the next formula:

$$
\mathrm{U}=U_{0}+m * \omega
$$


where $\mathrm{U}$ and $\mathrm{U}_{0}$ are representing the overall heat transfer coefficients after wetting and in dried state, $\mathrm{m}$ is the slope and $\omega$ is the moisture content one after the other. In these two cases (concrete and brick) all of the above mentioned plastic foam insulators can be used. For choosing those the pros and cons can only be their prices or their resistance against the outer physical and mechanical effects. In Figure 2 one can see the slopes (m) belonging to Eq. 6 taken from Figure 1.a and $\mathrm{b}$ in function of the used, different EPS materials. One belonging to the concrete and the other belonging to the brick, combined with the different test insulators. One can observe that the curve of the brick is highly above the curve of concrete. The data values are following linear increasing.

\subsection{The percental change in the $U$-values}

We calculated a percental change compared to the greatest amount of sorped water by using the next equation and represented in Figure 3:

$\mathrm{Y}(\%)=\frac{U_{95 \%}-U_{0}}{U_{o}} \times 100$

where $\mathrm{U}_{95 \%}$ is the overall heat transfer coefficients for the moisture content belonging to $95 \%$ relative humidity and $\mathrm{U}_{0}$ is the same value without any moisture for a given structure combination (eg. 0.4 m Brick+0.1 EPS 150 etc.). Figure 3 shows that for similar moisture contents the higher deviances can be observed in the values of brick then in the values of concrete. It should be noted that there similar decrease of in the two curves from EPS 30 to EPS 200. This can be referred to the density of the samples. The density of the EPS materials is increasing with the increasing EPS Label number (30, 100, 150 and 200). The highest density is the lowest moisture up taking capability. This phenomenon is clearly written in [1316]. Can be noticed that the highest percental change belongs to the EPS 30 and to the grey, however the lowest belongs to the EPS 200. For the concrete about 4 and for the brick nearly $6 \%$ percental changes were found by applying the graphite doped one. 


\section{Conclusions}

In this paper we presented possible applications of different EPS materials as additional insulations. Five different expanded polystyrene with $0.1 \mathrm{~m}$ thickness were tested (EPS 30, 100, 150, 200 and Grey). These materials were combined with concrete and with brick with $0.4 \mathrm{~m}$ thicknesses. We have shown that the change in the overall heat transfer coefficient of the wall structures is caused by on the one hand the water content, on the other hand the density of the insulating material. We verified that the water causes greater increase in the Uvalue of the brick than the concrete's. The highest degradation degree can be found at the application of the grey EPS. It can happen by the "nature" of this material. This grey EPS is pure polystyrene enhanced with carbon particles. Carbon has good getter properties and it has relatively low density, so these two parameters can cause the great water adsorbing capability. Furthermore, we can conclude that about 0.5-1\% water content can cause approximately 5$6 \%$ increasing in the U-value of a wall structure with $0.5 \mathrm{~m}$ thickness.

\section{Acknowledgements}

The work is supported by the TÁMOP-4.2.2.A-11/1/KONV-2012-0041 project. The project is co-financed by the European Union and the European Social Fund.

\section{References}

1. Stubberud, L., Arwidsson, G. H., Graffner, C. 1994. Water-solid interactions: I. A technique for studying moisture sorption/desorption, International Journal of Pharmaceutics. 114:55-64

2. Karoglou, M., Moropoulou, A., Maroulis, Z:B, and Krokida, M.K. Water sorption isotherms of some building materials, Drying Technology, 23:289-303, 2005 
3. Richards, R.F, Burch, D.M., Thomas, W.C. Water vapor sorption measurements of common building materials. ASHRAE Transactions. 98 (2), pp.475 1992

4. Scarpa, F., Tagliafico, L.A. A new procedure to measure water adsorption isotherms of porous fibrous materials, Journal of Porous materials 15:451-456 (2008)

5. Lakatos A., Kalmár F. Analysis of Water Sorption and Thermal Conductivity of Expanded Polystyrene Insulation Materials. Building Services Engineering Research and Technology 2013. 34 (4). 407-416

6. Lakatos A., Kalmár F. Investigation of thickness and density dependence of thermal conductivity of expanded polystyrene insulation materials. Materials and Structures (2013) 46:1101-1105

7. Lakatos A., Method for the determination of sorption isotherms of materials demonstarted through soil samples. Int. Rev. Appl. Sci. Eng. 2 (2011) 2, 117-121

8. Kalmár, F. Energy analysis of building thermal insulation. 11th Conference for Building Physics, Dresden, Deutschland 26-30 September 2002: p.103-112 (ISBN 386005-322-1)

9. Fekete I. (edited) (1985) Épületfizika kézikönyv. (Handbook of Building Physics), Műszaki Könyvkiadó, Budapest, ISBN:963 10642 X

10. Valovirta I., Vinha J. Water Vapor. Permeability and Thermal Conductivity as a Function of Temperature and Relative Humidity. http://www.ornl.gov/sci/buildings/2012/2004/077.PDF 2004.

11. Jerman M., Cerny R. : Effect of moisture content on heat and moisture transport and storage properties of thermal insulation materials Energy and Buildings 53 (2012) 3946 
12. Tariku F. Kumaran K, Fazio P. Transient model for coupled heat, air and moisture transfer through multilayered porous media. International Journal of Heat and Mass Transfer 53 (2010) 3035-3044

13. Sadauskiene J, Bliudzius R, Ramanauskas J, et al. Analysis of distribution of properties of expanded polystyrene in production and their changes in exploitation conditions. Mater Sci 2009; 15(4). ISSN 1392-1320.

14. Gnip IY, Kersulis V, Vejelis S, et al. Water absorption of expanded polystyrene boards. Polym Test 2006; 25: 635-641.

15. Vejelis S and Vaitkus S. Investigation of water absorption by expanded polystyrene slabs. Mater Sci Medz iagotyra) 2006; 12(2): 134-137

16. Lakatos A.: Investigation of water sorption properties of different insulating materials The 1st Virtual International Conference on Advanced Research in Scientific Areas (ARSA-2012) Slovakia, December 3 - 7, 2012: Proceedings in Advanced Research in Scientific Areas. Conference details: Zilina, Slovakia, 2012.12.03-2012.12.07. Zilina: EDIS, 2012. pp. 1827-1831. (ISBN:978-80-554-0606-0) 
Figure captions:

Figure 1.a: The calculated U-values in function of moisture content for $0.4 \mathrm{~m}$ thick Concrete wall in combination with different EPS materials with $0.1 \mathrm{~m}$ thicknesses

Figure 1.b: The calculated U-values in function of moisture content for $0.4 \mathrm{~m}$ thick Brick wall in combination with different EPS materials with $0.1 \mathrm{~m}$ thicknesses

Figure 2.: The slopes of the curves taken from Figure 1a and belonging to different EPS materials

Figure 3.: The percental changes of the U-values compared to the highest relative humidity (95\%) in function of the different EPS materials

Tables:

Table 1.: The used constants.

\begin{tabular}{|c|c|c|c|}
\hline $\mathbf{Z}_{\text {brick }}$ & 20 & $\mathbf{d}_{\text {b.c }}(\mathbf{m})$ & 0.4 \\
\hline $\mathbf{Z}_{\text {concrete }}$ & 12 & $\mathbf{d}_{\text {eps }}(\mathbf{m})$ & 0.1 \\
\hline $\mathbf{Z}_{\text {eps }}$ & 2 & $\mathbf{R}_{\text {i.e }}$ & {$\left[\mathbf{m}^{2} \mathbf{K} / \mathbf{W}\right]$} \\
\hline
\end{tabular}

Table 2. The data with EPS 30.

\begin{tabular}{|c|c|c|c|c|c|c|}
\hline EPS 30 /rh \% & $\mathbf{0 . 0 0}$ & $\mathbf{2 5 . 0 0}$ & $\mathbf{5 0 . 0 0}$ & $\mathbf{6 3 . 0 0}$ & $\mathbf{7 5 . 0 0}$ & $\mathbf{9 5 . 0 0}$ \\
\hline Moisture content (\%) & 0.0000 & 0.8800 & 0.8910 & 0.9200 & 0.9360 & 1.0460 \\
\hline Thermal conductivity [W/mK]. & & & & & & \\
brick & 0.7200 & 0.8467 & 0.8483 & 0.8525 & 0.8548 & 0.8706 \\
\hline
\end{tabular}




\begin{tabular}{|c|c|c|c|c|c|c|}
\hline $\begin{array}{l}\text { Thermal conductivity }[\mathrm{W} / \mathrm{mK}] \text {. } \\
\text { concrete }\end{array}$ & 0.7000 & 0.7739 & 0.7748 & 0.7773 & 0.7786 & 0.7879 \\
\hline \multicolumn{7}{|l|}{ Thermal conductivity [W/mK]. } \\
\hline EPS 30 & 0.0596 & 0.0607 & 0.0607 & 0.0607 & 0.0608 & 0.0609 \\
\hline $\mathbf{R}_{\mathrm{b}}\left[\mathbf{m}^{2} \mathbf{K} / \mathbf{W}\right]$ & 0.5556 & 0.4724 & 0.4715 & 0.4692 & 0.4680 & 0.4594 \\
\hline $\mathbf{R}_{\mathrm{c}}\left[\mathbf{m}^{2} \mathbf{K} / \mathbf{W}\right]$ & 0.5714 & 0.5168 & 0.5162 & 0.5146 & 0.5137 & 0.5077 \\
\hline $\mathbf{R}_{\text {eps }}\left[\mathbf{m}^{2} \mathbf{K} / \mathbf{W}\right]$ & 1.6767 & 1.6477 & 1.6474 & 1.6464 & 1.6459 & 1.6424 \\
\hline $\mathbf{U}_{\text {brick+eps }}\left[\mathbf{W} / \mathbf{m}^{2} \mathbf{K}\right]$ & 0.4168 & 0.4373 & 0.4375 & 0.4382 & 0.4385 & 0.4408 \\
\hline $\mathbf{U}_{\text {concrete+eps }}\left[\mathrm{W} / \mathbf{m}^{2} \mathbf{K}\right]$ & 0.4141 & 0.4290 & 0.4291 & 0.4296 & 0.4299 & 0.4316 \\
\hline Percental change. EPS 30+brick & 0.0000 & 4.9040 & 4.9608 & 5.1102 & 5.1923 & 5.7516 \\
\hline Percental change. EPS 30+concrete & 0.0000 & 3.5852 & 3.6284 & 3.7422 & 3.8049 & 4.2338 \\
\hline
\end{tabular}

Table 3.: The data with EPS 100

\begin{tabular}{|c|c|c|c|c|c|c|}
\hline EPS 100/rh \% & $\mathbf{0 . 0 0}$ & $\mathbf{2 5 . 0 0}$ & $\mathbf{5 0 . 0 0}$ & $\mathbf{6 3 . 0 0}$ & $\mathbf{7 5 . 0 0}$ & $\mathbf{9 5 . 0 0}$ \\
\hline Moisture content (\%) & 0.0000 & 0.7930 & 0.8400 & 0.8500 & 0.8600 & 0.9800 \\
\hline Thermal conductivity [W/mK]. & & & & & & \\
\hline Thermal conductivity [W/mK]. & & & & & \\
\hline concrete & 0.7200 & 0.8342 & 0.8410 & 0.8424 & 0.8438 & 0.8611 \\
\hline $\mathbf{1 0 0}$ & 0.7000 & 0.7666 & 0.7706 & 0.7714 & 0.7722 & 0.7823 \\
\hline $\mathbf{R}_{\mathbf{b}}\left[\mathbf{m}^{2} \mathbf{K} / \mathbf{W}\right]$ & 0.0540 & 0.0548 & 0.0549 & 0.0549 & 0.0549 & 0.0550 \\
\hline $\mathbf{R}_{\mathbf{c}}\left[\mathbf{m}^{2} \mathbf{K} / \mathbf{W}\right]$ & 0.5556 & 0.4795 & 0.4756 & 0.4748 & 0.4740 & 0.4645 \\
\hline $\mathbf{R}_{\mathbf{e p s}}\left[\mathbf{m}^{2} \mathbf{K} / \mathbf{W}\right]$ & 0.5714 & 0.5218 & 0.5191 & 0.5185 & 0.5180 & 0.5113 \\
\hline & 1.8532 & 1.8243 & 1.8226 & 1.8222 & 1.8219 & 1.8176 \\
\hline
\end{tabular}




\begin{tabular}{|c|l|l|l|l|l|l|}
\hline $\mathbf{U}_{\text {brick+eps }}\left[\mathbf{W} / \mathbf{m}^{\mathbf{2}} \mathbf{K}\right]$ & 0.3883 & 0.4048 & 0.4057 & 0.4059 & 0.4061 & 0.4084 \\
\hline $\mathbf{U}_{\text {concrete+eps }}\left[\mathbf{W} / \mathbf{m}^{\mathbf{2}} \mathbf{K}\right]$ & 0.3859 & 0.3980 & 0.3987 & 0.3988 & 0.3990 & 0.4007 \\
\hline Percental change. EPS 100+brick & 0.0000 & 4.2495 & 4.4841 & 4.5337 & 4.5833 & 5.1728 \\
\hline Percental change. EPS 100+concrete & 0.0000 & 3.1275 & 3.3067 & 3.3448 & 3.3828 & 3.8370 \\
\hline
\end{tabular}

Table 4: The data with EPS 150

\begin{tabular}{|c|c|c|c|c|c|c|}
\hline EPS 150 /rh \% & $\mathbf{0 . 0 0}$ & $\mathbf{2 5 . 0 0}$ & $\mathbf{5 0 . 0 0}$ & $\mathbf{6 3 . 0 0}$ & $\mathbf{7 5 . 0 0}$ & $\mathbf{9 5 . 0 0}$ \\
\hline Moisture content (\%) & 0.0000 & 0.6000 & 0.6200 & 0.6500 & 0.6700 & 0.8700 \\
\hline Thermal conductivity [W/mK]. brick & 0.7200 & 0.8064 & 0.8093 & 0.8136 & 0.8165 & 0.8453 \\
\hline Thermal conductivity [W/mK]. & & & & & & \\
concrete & 0.7000 & 0.7504 & 0.7521 & 0.7546 & 0.7563 & 0.7731 \\
\hline Thermal conductivity [W/mK]. EPS & & & & & & \\
\hline $\mathbf{R}_{\mathbf{b}}\left[\mathbf{m}^{\mathbf{2}} \mathbf{K} / \mathbf{W}\right]$ & 0.0511 & 0.0517 & 0.0518 & 0.0518 & 0.0518 & 0.0520 \\
\hline $\mathbf{R}_{\mathbf{c}}\left[\mathbf{m}^{\mathbf{2}} \mathbf{K} / \mathbf{W}\right]$ & 0.5556 & 0.4960 & 0.4943 & 0.4916 & 0.4899 & 0.4732 \\
\hline $\mathbf{R}_{\text {eps }}\left[\mathbf{m}^{\mathbf{2}} \mathbf{K} / \mathbf{W}\right]$ & 0.5714 & 0.5330 & 0.5319 & 0.5301 & 0.5289 & 0.5174 \\
\hline $\mathbf{U}_{\text {brick+eps }}$ [W/m $\left.{ }^{2} \mathbf{K}\right]$ & 1.9562 & 1.9330 & 1.9322 & 1.9311 & 1.9303 & 1.9227 \\
\hline $\mathbf{U}_{\text {concrete+eps }}$ [W/m $\left.{ }^{2} \mathbf{K}\right]$ & 0.3734 & 0.3853 & 0.3856 & 0.3862 & 0.3866 & 0.3902 \\
\hline Percental change. EPS 150+brick & 0.0000 & 3.1868 & 3.2874 & 3.4378 & 3.5376 & 4.5186 \\
\hline Percental change. EPS 150+concrete & 0.0000 & 2.3389 & 2.4149 & 2.5287 & 2.6045 & 3.3556 \\
\hline
\end{tabular}


Table 5.: The data with EPS 200

\begin{tabular}{|c|c|c|c|c|c|c|}
\hline EPS $200 /$ rh \% & 0.00 & 25.00 & 50.00 & 63.00 & 75.00 & 95.00 \\
\hline Moisture content (\%) & 0.0000 & 0.5000 & 0.5250 & 0.5350 & 0.5680 & 0.6885 \\
\hline Thermal conductivity [W/mK]. & & & & & & \\
\hline brick & 0.7200 & 0.7920 & 0.7956 & 0.7970 & 0.8018 & 0.8191 \\
\hline Thermal conductivity [W/mK]. & & & & & & \\
\hline concrete & 0.7000 & 0.7420 & 0.7441 & 0.7449 & 0.7477 & 0.7578 \\
\hline Thermal conductivity [W/mK]. EPS & & & & & & \\
\hline 200 & 0.0483 & 0.0488 & 0.0488 & 0.0488 & 0.0488 & 0.0489 \\
\hline $\mathbf{R}_{\mathrm{b}}\left[\mathbf{m}^{2} \mathbf{K} / \mathbf{W}\right]$ & 0.5556 & 0.5051 & 0.5028 & 0.5019 & 0.4989 & 0.4883 \\
\hline $\mathbf{R}_{\mathrm{c}}\left[\mathbf{m}^{2} \mathbf{K} / \mathbf{W}\right]$ & 0.5714 & 0.5391 & 0.5376 & 0.5370 & 0.5350 & 0.5278 \\
\hline $\mathbf{R}_{\mathrm{eps}}\left[\mathbf{m}^{2} \mathbf{K} / \mathbf{W}\right]$ & 2.0713 & 2.0507 & 2.0497 & 2.0493 & 2.0480 & 2.0431 \\
\hline $\mathbf{U}_{\text {brick+eps }}\left[\mathbf{W} / \mathbf{m}^{2} \mathbf{K}\right]$ & 0.3580 & 0.3673 & 0.3678 & 0.3679 & 0.3685 & 0.3706 \\
\hline $\mathbf{U}_{\text {concrete+eps }}\left[\mathbf{W} / \mathbf{m}^{2} \mathbf{K}\right]$ & 0.3560 & 0.3628 & 0.3631 & 0.3632 & 0.3637 & 0.3653 \\
\hline Percental change. EPS 200+brick & 0.0000 & 2.6084 & 2.7329 & 2.7826 & 2.9459 & 3.5349 \\
\hline Percental change. EPS 200+concrete & 0.0000 & 1.9174 & 2.0112 & 2.0487 & 2.1722 & 2.6206 \\
\hline
\end{tabular}


Table 6.: The data with EPS grey

\begin{tabular}{|c|c|c|c|c|c|c|}
\hline EPS Grey /rh \% & $\mathbf{0 . 0 0}$ & $\mathbf{2 5 . 0 0}$ & $\mathbf{5 0 . 0 0}$ & $\mathbf{6 3 . 0 0}$ & $\mathbf{7 5 . 0 0}$ & $\mathbf{9 5 . 0 0}$ \\
\hline Moisture content (\%) & 0.0000 & 1.0100 & 1.0500 & 1.0900 & 1.1160 & 1.1600 \\
\hline Thermal conductivity [W/mK]. brick & 0.7200 & 0.8654 & 0.8712 & 0.8770 & 0.8807 & 0.8870 \\
\hline Thermal conductivity [W/mK]. concrete & 0.7000 & 0.7848 & 0.7882 & 0.7916 & 0.7937 & 0.7974 \\
\hline Thermal conductivity [W/mK]. EPS & & & & & & \\
\hline Grey & 0.0454 & 0.0464 & 0.0464 & 0.0464 & 0.0465 & 0.0465 \\
\hline $\mathbf{R}_{\mathbf{b}}\left[\mathbf{m}^{\mathbf{2}} \mathbf{K} / \mathbf{W}\right]$ & 0.5556 & 0.4622 & 0.4591 & 0.4561 & 0.4542 & 0.4509 \\
\hline $\mathbf{R}_{\mathbf{c}}\left[\mathbf{m}^{2} \mathbf{K} / \mathbf{W}\right]$ & 0.5714 & 0.5097 & 0.5075 & 0.5053 & 0.5039 & 0.5016 \\
\hline $\mathbf{R}_{\text {eps }}\left[\mathbf{m}^{\mathbf{2}} \mathbf{K} / \mathbf{W}\right]$ & 2.2007 & 2.1571 & 2.1554 & 2.1538 & 2.1527 & 2.1508 \\
\hline $\mathbf{U}_{\text {brick+eps }}$ [W/m $\left.{ }^{2} \mathbf{K}\right]$ & 0.3421 & 0.3589 & 0.3596 & 0.3602 & 0.3606 & 0.3612 \\
\hline $\mathbf{U}_{\text {concrete+eps }}$ [W/m $\left.{ }^{2} \mathbf{K}\right]$ & 0.3403 & 0.3529 & 0.3534 & 0.3539 & 0.3542 & 0.3547 \\
\hline Percental change. EPS grey+brick & 0.0000 & 4.9152 & 5.0942 & 5.2723 & 5.3874 & 5.5814 \\
\hline Percental change. EPS grey+concrete & 0.0000 & 3.7179 & 3.8595 & 4.0007 & 4.0923 & 4.2469 \\
\hline
\end{tabular}

Table 7. The calaculated insulation thicknesses for the insulating materials

\begin{tabular}{|c|c|c|}
\hline & Brick & Concrete \\
\hline $\mathbf{U}_{\mathbf{2 0 0 6}}\left[\mathbf{W} / \mathbf{m}^{\mathbf{2}} \mathbf{K}\right]=\mathbf{0 . 4 5}$ & \multicolumn{2}{|c|}{$\mathrm{d}[\mathrm{m}]$} \\
\hline EPS 30 & 0.09 & 0.09 \\
\hline EPS 100 & 0.08 & 0.08 \\
\hline EPS 150 & 0.08 & 0.08 \\
\hline EPS 200 & 0.07 & 0.07 \\
\hline EPS Grey & 0.07 & 0.07 \\
\hline
\end{tabular}




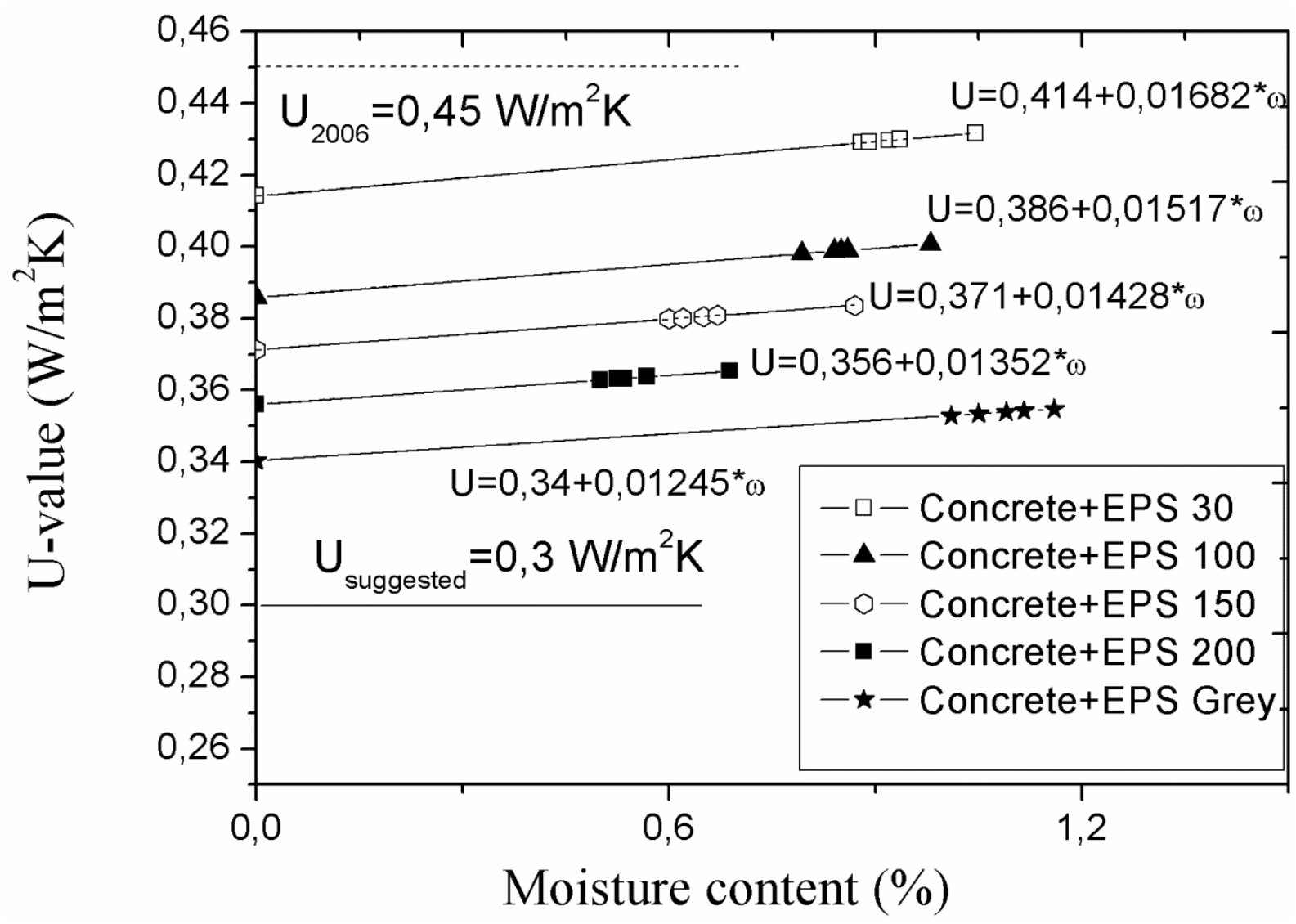

Figure 1.a: The calculated U-values in function of moisture content for $0.4 \mathrm{~m}$ thick Concrete wall in combination with different EPS materials with $0.1 \mathrm{~m}$ thicknesses 


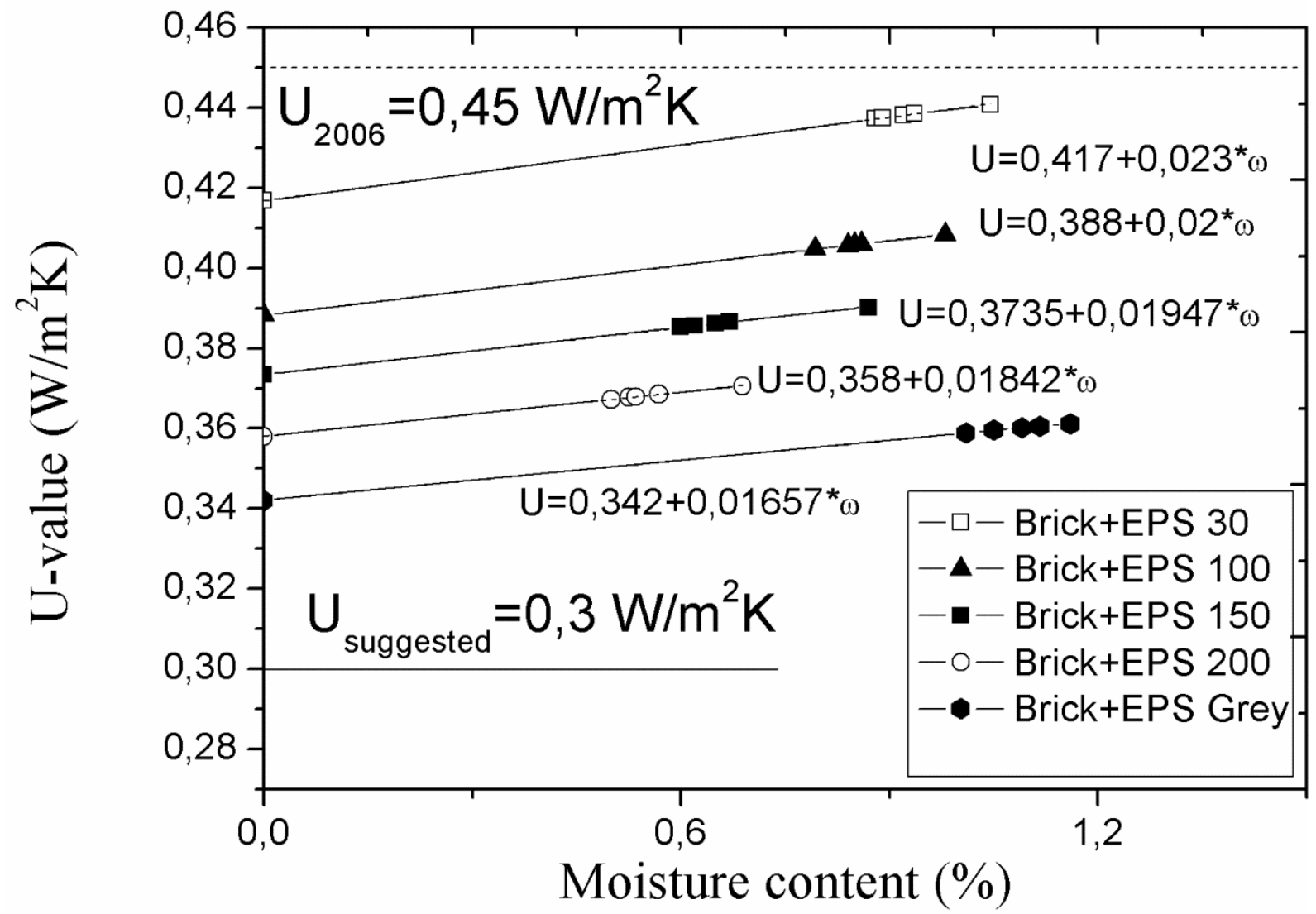

Figure 1.b: The calculated U-values in function of moisture content for $0.4 \mathrm{~m}$ thick Brick wall in combination with different EPS materials with $0.1 \mathrm{~m}$ thicknesses 


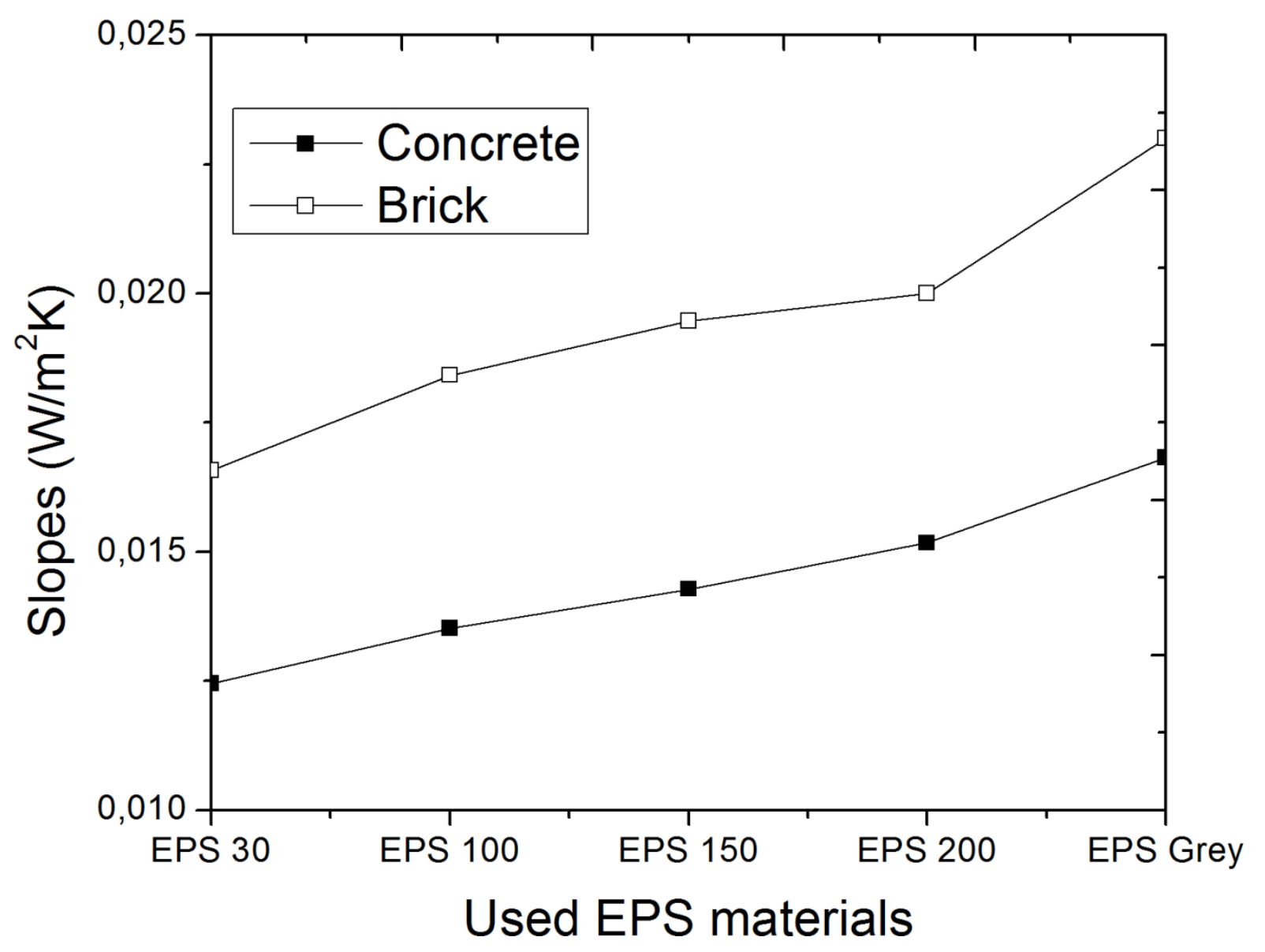

Figure 2.: The slopes of the curves taken from Figure 1a and b belonging to different EPS materials 


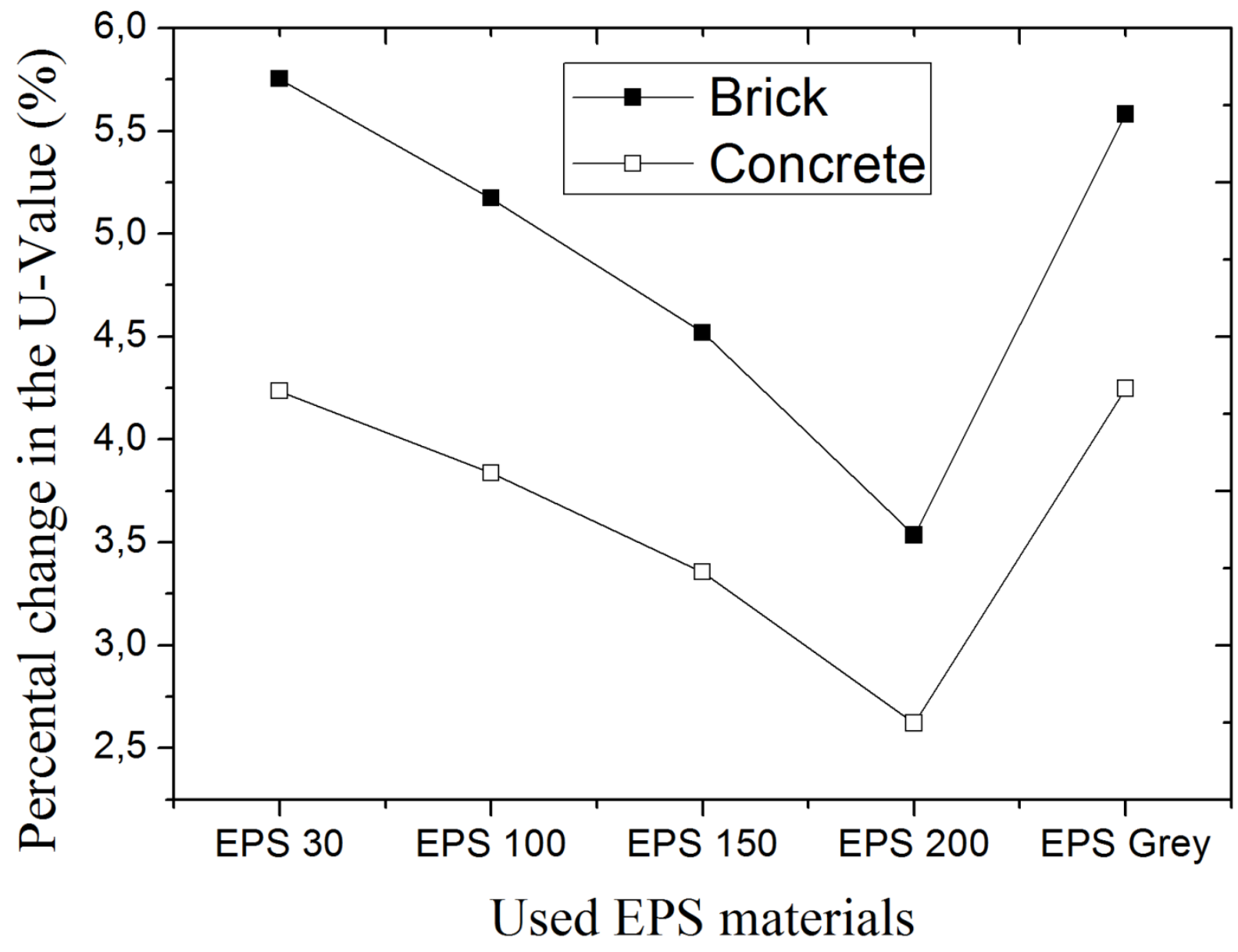

Figure 3.: The percental changes of the U-values compared to the highest relative humidity (95\%) in function of the different EPS materials 